\title{
The complexities of resynchronizing scar
}

\author{
Kenneth C. Bilchick, M.D., M.S., F.A.C.C., F.H.R.S.
}

\section{See related article, pp. 1049-1059}

In the current issue of the Journal, Zizek et $\mathrm{al}^{1}$ report their findings regarding the relationship between myocardial perfusion abnormalities, left ventricular lead position, and ventricular tachyarrhythmias (VT/VF) in 57 patients undergoing single-photon emission computed tomography (SPECT) myocardial perfusion imaging prior to cardiac resynchronization therapy (CRT). The major findings were that both decreased overall viability and decreased regional viability at the left ventricular (LV) lead implantation site were the only independent predictors of VT/VF during follow-up in separate multivariate models.

Because overall viability and regional viability were significantly correlated, both covariates were not evaluated in the same predictive multivariable model. As a result, it is possible that only one of these covariates had a true causal relationship with the occurrence of VT/VF, and the other was a confounder. Regardless, the fact that no other covariate independently predicted ventricular arrhythmias suggests that there is an important relationship between viability based on SPECT and ventricular arrhythmias in patients with systolic heart failure referred for CRT, even if the mechanism is not fully understood.

In this study, overall and regional viability were also independent predictors of VT/VF in the 41 patients without any prior history of these arrhythmias. By implicating viability in the region of the LV lead as a cause of these arrhythmias, the study seems to imply that CRT increases the risk of VT/VF in selected patients. This may or may not be true. We do know that

From the Department of Medicine, Cardiovascular Division, University of Virginia Health System, Charlottesville, USA ${ }^{\text {a }}$

Received for publication Sep 25, 2013; final revision accepted Sep 25, 2013.

Reprint requests: Kenneth C. Bilchick, M.D., M.S., F.A.C.C., F.H.R.S., Department of Medicine, Cardiovascular Division, University of Virginia Health System, P.O. Box 800158, Charlottesville, VA 22908, USA; bilchick@virginia.edu.

J Nucl Cardiol 2013;20:966-8.

$1071-3581 / \$ 34.00$

Copyright (c) 2013 American Society of Nuclear Cardiology.

doi:10.1007/s12350-013-9796-x increasing myocardial scar increases the risk of VT/VF in patients with heart failure without CRT. ${ }^{2,3}$ Did CRT really increase the burden of VT/VF beyond the baseline risk predicted by the presence of scar? The study design does not directly address this question because there was not a comparable control group of patients with heart failure, left bundle branch block (LBBB), and myocardial scar who did not undergo CRT implantation. Only such a study with a control group not receiving CRT would facilitate more definitive conclusions regarding whether CRT actually causes ventricular arrhythmias in heart failure patients with overall decreased viability and/or decreased viability at the LV lead implantation site.

There are a number of potential mechanisms by which CRT might increase or decrease the risk of different types of ventricular arrhythmias. Monomorphic VT is typically initiated by a premature ventricular beat and maintained by scar, ${ }^{4}$ while torsade de pointe is triggered by early after depolarizations (EADs) and maintained by functional reentry. This latter category of arrhythmias is more likely in patients with baseline abnormalities in repolarization that can be exacerbated by left ventricular epicardial pacing. In one study, left ventricular epicardial pacing was shown to increase the QT interval and transmural dispersion of repolarization in 29 patients with heart failure ${ }^{5}$. Early extrasystoles were frequently observed in four patients with biventricular pacing and left ventricular epicardial pacing, of whom one developed multiple episodes of nonsustained polymorphic ventricular tachycardia, and another had incessant torsade de pointes. Of note, these arrhythmias were inhibited with right ventricular endocardial pacing. In rabbit experiments from the same study, epicardial pacing relative to endocardial pacing produced a net increase of $17 \pm 5$ and $22 \pm 5 \mathrm{~ms}$ in the QT interval and transmural dispersion of repolarization, respectively. ${ }^{5}$

The effects of LV epicardial pacing on repolarization may be explained by the distinct properties of the different myocardial layers. Although ventricular activation from the His Purkinje system starts in the endocardium and spreads to the epicardium, the epicardium actually repolarizes first because it has a shorter action potential duration. ${ }^{6}$ As a result, epicardial pacing prolongs repolarization in the endocardium with its longer baseline action potential duration, leading to an increase in the QT interval and prolongation of the 
transmural dispersion of repolarization. Because structural heart disease may be associated with increased transmural dispersion of repolarization and EADs at baseline, these additional increases in the QT interval and transmural dispersion of repolarization caused by epicardial pacing may be enough to cause polymorphic VT in selected patients with CRT.

The mechanisms of monomorphic ventricular tachycardia associated with scar $^{4}$ are different from those associated with torsade de pointes. Overall scar burden and border zone scar were highly predictive of VT/VF in a recent cohort of CRT patients, ${ }^{7}$ consistent with previous prior studies showing the importance of myocardium containing both scar and viable tissue in the genesis of ventricular tachycardia. ${ }^{8}$ In contrast to the potentially negative effects of epicardial pacing on repolarization, other studies have shown that CRT may decrease the risk of arrhythmias in patients with heart failure and scar. ${ }^{9-11}$ Potential mechanisms by which CRT may decrease risk in these patients include a decrease in intraventricular conduction delays, fewer pause-dependent tachyarrhythmias, beneficial neurohormonal effects, more efficient myocardial metabolism, and LV reverse remodeling. ${ }^{12}$

Regarding metabolism, myocardial efficiency was evaluated in a study of ten patients with dilated cardiomyopathy and LBBB, in which the metabolic effects of CRT were compared with inotrope therapy. ${ }^{13}$ The improvement in $\mathrm{d} P / \mathrm{d} t$ max with CRT was also associated with decreased myocardial oxygen consumption. In contrast, the increased contractility with dobutamine was associated with increased myocardial oxygen consumption. In this way, CRT is associated with improved mechano-energetics compared with cyclic AMP-calcium-dependent inotropic interventions. Reverse remodeling results in improvement in ejection fraction and left ventricular volumes during the 3-6 months after implantation ${ }^{14}$ and may also decrease arrhythmia risk. Over time, reverse remodeling and improved mechanoenergetics may be expected to decrease vulnerability to VT/VF in CRT responders and outweigh the potentially arrhythmogenic effects of LV epicardial pacing. Patients who are not effectively resynchronized would not be expected to derive these benefits. As a result, if there is an increased risk of arrhythmias resulting from CRT in selected patients, it may be in the CRT nonresponders.

What conclusions can be made regarding the association between the decreased viability in the region with the LV lead position and increased VT/VF risk? Posterolateral scar on CMR has been associated with CRT nonresponse in multiple studies, ${ }^{15,16}$ presumably because the LV lead is frequently implanted in this region, and it may be difficult to positively alter LV mechanics and induce reverse remodeling by pacing into scar. In fact, pacing at sites of akinesis by echocardiography has been also been associated with CRT nonresponse. ${ }^{17}$ In this study, over $70 \%$ of patients had posterolateral implant sites. ${ }^{1}$ As a result, it is possible that the increased risk of VT/VF at LV lead implant sites with reduced viability may reflect that fact that patients with scar in the area of the final lead position are less likely to experience the "antiarrhythmic"' effect of LV reverse remodeling. In fact, Zizek et al ${ }^{1}$ showed that the presence of LV reverse remodeling was significantly higher in patients without VT than in patients with VT (64.1\% vs $16.7 \% ; P=0.001)$. Alternatively, the increased risk of VT/VF in patients with decreased viability at the lead implant site may represent merely the confounding association between regional and overall viability, as previously discussed.

In summary, this study by Zizek et al demonstrates that SPECT can be used to identify viability characteristics associated with an increased risk of VT/VF. Regarding the overall clinical impact, SPECT and CMR imaging of viability and scar may eventually help to identify patients with an increased risk of VT/VF who stand to benefit most from CRT defibrillators as opposed to CRT pacemakers. ${ }^{18}$ In comparison to CMR, SPECT, of course, also has the benefit that it can be performed routinely in patients referred for CRT upgrade procedures. Even so, several questions remain unanswered at this point, such as whether LV pacing in an area of decreased viability really has an arrhythmogenic effect, as suggested in this report. These questions will hopefully be addressed by future clinical studies.

\section{Acknowledgment}

This study was supported by NIH Grant K23 HL094761.

\section{Disclosures}

Dr. Bilchick is supported by a K23 award from the National Heart, Lung, and Blood Institute (HL094761).

\section{References}

1. Zizek D, Cvijic M, Lezaic L, Guzic B, Zupan I. Impact of myocardial viability assessed by myocardial perfusion imaging on ventricular tachyarrhythmias in cardiac resynchronization therapy. J Nucl Cardiol. 2013. doi:10.1007/s12350-013-9795-y.

2. Nazarian S, Bluemke DA, Lardo AC, Zviman MM, Watkins SP, Dickfeld TL, et al. Magnetic Resonance Assessment of the Substrate for Inducible Ventricular Tachycardia in Nonischemic Cardiomyopathy. Circulation. 2005;112:2821-5.

3. Bello D, Fieno DS, Kim RJ, Pereles FS, Passman R, Song G, et al. Infarct Morphology Identifies Patients with Substrate for Sustained Ventricular Tachycardia. J Am Coll Cardiol. 2005;45:1104-8. 
4. Stevenson WG, Khan H, Sager P, Saxon LA, Middlekauff HR, Natterson PD, et al. Identification of Reentry Circuit Sites During Catheter Mapping and Radiofrequency Ablation of Ventricular Tachycardia Late After Myocardial Infarction. Circulation. 1993;88:1647-70.

5. Medina-Ravell VA, Lankipalli RS, Yan GX, Antzelevitch C, Medina-Malpica NA, Medina-Malpica OA, et al. Effect of Epicardial or Biventricular Pacing to Prolong QT Interval and Increase Transmural Dispersion of Repolarization: Does Resynchronization Therapy Pose a Risk for Patients Predisposed to Long QT Or Torsade De Pointes? Circulation. 2003;107:740-6.

6. Yan GX, Antzelevitch C. Cellular Basis for The Normal T Wave and the Electrocardiographic Manifestations of the Long-QT syndrome. Circulation. 1998;98:1928-36.

7. Fernandez-Armenta J, Berruezo A, Mont L, Sitges M, Andreu D, Silva E, et al. Use of Myocardial Scar Characterization to Predict Ventricular Arrhythmia in Cardiac Resynchronization Therapy. Europace. 2012;14:1578-86.

8. Schmidt A, Azevedo CF, Cheng A, Gupta SN, Bluemke DA, Foo TK, et al. Infarct tissue Heterogeneity by Magnetic Resonance Imaging Identifies Enhanced Cardiac Arrhythmia Susceptibility in Patients with Left Ventricular Dysfunction. Circulation. 2007;115:2006-14.

9. Higgins SL, Yong P, Sheck D, McDaniel M, Bollinger F, Vadecha $\mathrm{M}$, et al. Biventricular Pacing Diminishes the Need for Implantable Cardioverter Defibrillator Therapy. Ventak CHF Investigators. J Am Coll Cardiol. 2000;36:824-7.

10. Garrigue S, Barold SS, Hocini M, Jais P, Haissaguerre M, Clementy J. Treatment of Drug Refractory Ventricular Tachycardia by Biventricular Pacing. Pacing Clin Electrophysiol. 2000;23:1700-2.

11. Zagrodzky JD, Ramaswamy K, Page RL, Joglar JA, Sheehan CJ, Smith ML, et al. Biventricular Pacing Decreases the Inducibility of
Ventricular Tachycardia in Patients with Ischemic Cardiomyopathy. Am J Cardiol. 2001;87:1208-10.

12. Bilchick KC, Helm RH, Kass DA. Physiology of Biventricular Pacing. Curr Cardiol Rep. 2007;9:358-65.

13. Nelson GS, Berger RD, Fetics BJ, Talbot M, Spinelli JC, Hare JM, et al. Left Ventricular or Biventricular Pacing Improves Cardiac Function at Diminished Energy Cost in Patients with Dilated Cardiomyopathy and Left Bundle-Branch Block. Circulation. 2000;102:3053-9.

14. Yu CM, Chau E, Sanderson JE, Fan K, Tang MO, Fung WH, et al. Tissue Doppler Echocardiographic Evidence of Reverse Remodeling and Improved Synchronicity by Simultaneously Delaying Regional Contraction After Biventricular Pacing Therapy in Heart Failure. Circulation. 2002;105:438-45.

15. Bleeker GB, Kaandorp TA, Lamb HJ, Boersma E, Steendijk P, de Roos A, et al. Effect of Posterolateral Scar Tissue on Clinical and Echocardiographic Improvement After Cardiac Resynchronization Therapy. Circulation. 2006;113:969-76.

16. White JA, Yee R, Yuan X, Krahn A, Skanes A, Parker M, et al. Delayed Enhancement Magnetic Resonance Imaging Predicts Response to Cardiac Resynchronization Therapy in Patients with Intraventricular Dyssynchrony. J Am Coll Cardiol. 2006;48:1953-60.

17. Ypenburg C, van Bommel RJ, Delgado V, Mollema SA, Bleeker GB, Boersma E, et al. Optimal Left Ventricular Lead Position Predicts Reverse Remodeling and Survival After Cardiac Resynchronization Therapy. J Am Coll Cardiol. 2008;52:1402-9.

18. Tracy CM, Epstein AE, Darbar D, DiMarco JP, Dunbar SB, Estes NA III, et al. 2012 ACCF/AHA/HRS Focused Update of the 2008 Guidelines for Device-Based Therapy of Cardiac Rhythm Abnormalities: A Report of the American College of Cardiology Foundation/American Heart Association Task Force on Practice Guidelines. J Am Coll Cardiol. 2012;60:1297-313. 